\title{
The Relative Contribution of Higher-Order Thinking in Predicting Psychological Hardiness of University Students
}

\author{
Mohamed Sayed Mohamed Abdellatif ${ }^{1} \&$ Mervat Azmy Zaki Abdel-Gawad ${ }^{2}$ \\ 1 Associate Professor of Educational Psychology, Faculties of Education at Prince Sattam bin Abdul-Aziz \\ University, and Al-Azhar University, Assuit, Egypt \\ ${ }^{2}$ Associate Professor of Mental Health and Special Education at Prince Sattam bin Abdul-Aziz University, and \\ Minia University, Egypt \\ Correspondence: Mohamed Sayed Mohamed Abdel-Latif, Faculty of Education at Prince Sattam bin Abdul-Aziz \\ University, Saudi Arabia. Tel: 96-653-238-5349. E-mail: m.heby@ psau.edu.sa
}

Received: June 17, 2020

doi:10.5539/ass.v16n8p68
Accepted: June 28, $2020 \quad$ Online Published: July 22, 2020

URL: https://doi.org/10.5539/ass.v16n8p68

\begin{abstract}
Higher order thinking skills include critical, logical, reflective, metacognitive, and creative thinking. They are activated when individuals encounter unfamiliar problems, uncertainties, questions, or dilemmas. They play an important role in developing University students to encounter any stressful situations. This study aims at identifying the extent to which higher-order thinking degrees contribute to predicting the psychological hardiness of university students and at identifying the differences between males and females in higher-order thinking skills and psychological hardiness The higher order thinking scale (prepared by the researchers) and the psychological hardiness scale (by Mukhaimar, 1996) were completed by (485) male and female Minia University students. The current research adopted the descriptive research approach. According to the statistical analysis, results revealed that there was a statistically significant positive relationship between higher-order thinking and psychological hardiness among the study sample and there were no statistically significant differences between males and females in higher-order thinking. In addition, higher-order thinking skills contributed holistically in predicting the psychological hardiness among the university students. This study recommended that higher order thinking skills should be an integral part of higher education. Lastly, this study offers specific suggestions for higher education stakeholders.
\end{abstract}

Keywords: higher-order thinking, psychological hardiness, university students, relative contribution

\section{Introduction}

\subsection{Background}

Psychological hardiness is a relatively recent term in the field of positive psychology that contributes to the individual's psychological and physical health when exposing to stressful events. It plays an effective role in recognizing difficult events and interpreting them positively, enhancing the individual's emotional maturity, and increasing his experience to face stressful situations (Maddi, 2013). Kobasa, Maddi, Paccetti \& Zola (1985) stated that psychological hardiness is the personality pattern consisting of a set of interrelated attitudes that include commitment versus feeling alienated, controlling versus feeling helpless, and challenging versus feeling threatened, and these attitudes help the individual to cope with stressful events.

Developing higher-order thinking prepares the university students to face life conditions and problems, correctly build their personalities, and qualifying them to be good members who can participate in their society's development. Higher-order thinking skills are adaptive skills through which an individual can control his severe emotions and use appropriate methods to reach the best alternatives for dealing with the topic under stress. Higher-order thinking skills include critical, creative, and reflective thinking skills, as well as many other related thinking skills such as logical and abstract thinking (Lipman, 1991; Newman, 1991).

Recently, higher-order thinking is an educational concept that educators have begun to take into consideration to achieve the teaching and learning process goals. It allows the student to use his energies and mental skills to achieve success and adjustment within the educational field in particular and life in general.

Psychological hardiness is related to some patterns of higher-order thinking such as critical, creative, inductive, 
positive, and rational thinking. In this context, many previous studies indicated that some thinking styles are related to reducing stress, dealing with it effectively and predicting health outcomes, concluding that thinking styles affect facing stressful situations and problem-solving (Shaheen \& Al Said, 2012; Muhammad, 2013; Hammad, 2015; Naseem \& Khalid, 2010; Tugade \& Fredrickson, 2004).

Higher-order thinking occurs when the learner obtains new information, saving it into the memory, and linking it with the existing knowledge, then generating it again to be used in achieving a certain goal or solve a problem (Yee et al., 2015). The knowledge obtained through higher-order thinking processes is more easily transformable, so learners who have a deep understanding of an idea will be able to apply this knowledge in solving a new problem (Ramos, Dolipas, \& Villamor, 2013).

\subsection{Higher-order Thinking}

The cognitive trend is one of the most important approaches in psychology, which focuses on higher-order thinking and skills concerned with this type of thinking. Furthermore, higher-order thinking is one of the educational dimensions that educators have begun to take into consideration in the recent years as one of the significant keys for achieving the educational goals of the teaching and learning processes; as it ensures the effective knowledge development that allows the learner to use his maximum mental energies to achieve success and proper adaptation in the educational field and public life (Al-Atoum et al., 2007). Higher-order thinking reflects a thinking mode that necessitates a special mental effort, patience for suspicion and ambiguity, and independence in the practice of mental judgment as expanding the boundaries of knowledge about what has been discovered because it indicates a response to a challenge and posing challenges to other challenges (Lipman, 1991).

Resnick (1987) defined higher-order thinking as a set of detailed mental activities that require mental judgment, an analysis of complex situations according to multiple criteria, including many solutions, and avoiding simple solutions of formulations. He stated that the thinkers' task is to create or discover meaning the meaning despite the lack of clarity of an experience or a situation. Lipman (1991) described higher-order thinking as concept-rich thinking, which includes a self-organizing of the thinking process and seeking to explore continuously. But if the state of thinking presented for examination lacks these traits (conceptual richness, self-organization, exploration, and curiosity), then it is doubtful to consider it as a state of higher-order thinking. Also, instilling high-level cognitive skills among students will result in higher-order thinking for them.

Newman (1991) determined higher-order thinking as the ability to use mental processes comprehensively. This occurs when the learner interprets, analyzes, and processes the information to answer a question or solves a problem that cannot be solved through the routine use of previously learned information. This type of thinking includes the skills of critical, creative, inferential, inductive, and divergent thinking. It is a process of reasoning consisting of a series of complex procedures such as analysis, synthesis, comparison, reasoning, interpretation, evaluation, inductive and deductive reasoning (Zohar \& Dori, 2003). The researchers defined it procedurally as employing the individual mental processes to solve a problem or achieve a certain goal, including self-organization of the thinking process, combining between its components of critical thinking and creative thinking skills. It is expressed procedurally through the degree that the participant obtained in the high-level thinking scale under the current research. Higher-order thinking includes:

- Critical Thinking: The researchers procedurally defined it as a unique type of thinking in which the individual's ability to organize his efforts, examine his ideas carefully, formulate logical inferences, and calculate probabilities that leading to suitable conclusions and solutions to problems and achieving goals is clear. The critical personality traits focus on the following six dimensions:

1. The knowledge dimension: It includes the ability to challenge, critical imagination, thoughtful risk, cognitive flexibility, and tolerance of ambiguity.

2. Understanding logical rules dimension: It includes knowledge of logical rules, attachments, rational organization, and revealing the fallacies during discussion.

3. The ability to interpret dimension: It includes the ability to discover, debate, discuss and the tendency towards cognitive consistency, the rational interpretation of life phenomena, and the application of knowledge.

4. The affective domain: It involves being able to adapt new situations, self-confidence, high degree of balance, accepting other opinions, and being active and effective.

5. The sensitivity towards problem dimension: It includes sensitivity to problems, the ability to make correct assumptions, and identifying problems in a logical manner. 
6. The evaluation dimension: It includes the ability to make judgments, correct arguments, and the ability to infer (Mukhaimar, 1996)

- Creative Thinking: The researchers defined it procedurally as the way of viewing the problems or solutions from a new perspective that indicated unconventional solutions. The creative personality traits concentrate on the following dimensions:

1. Fluency: It is the student's ability to produce many ideas that are specialized in the subject of thinking in a specific period of time, which provides him with many solutions and options that are suitable for their application on the ground.

2. Originality: It is the student's ability to produce the student ideas and practices characterized by novelty and non-popularity.

3. Flexibility: It is the student's ability to produce the largest possible number of diverse and atypical ideas and practices related to his academic and life tasks.

4. Problem Sensitivity: It is the student's ability to predict possible problems in the situations they face, and to plan well to deal with them and process them.

5. Elaboration: It is the student's ability to develop and improve ideas and skills by adding details and clarifications to them that help in developing, enriching and implementing them (Lipman, 1991)

Limpan (1991) declared that higher-level thinking contains "twin pillars" the critical and creative thinking, and summarizes the process of higher-order thinking as an interaction between critical and creative thinking, while Nickerson (1999) discriminated between creative and critical thinking. He described creative thinking as broad, innovative, and unrestricted thinking associated with exploration and generation of ideas however, critical thinking focuses on disciplined, logical, and restricted thinking. He mentioned that creative and critical thinking has independent dimensions that must be enhanced together.

Educational literature (Beyer, 1987; Paul, 1990; Swartz \& Perkins, 1990) indicated that higher-order thinking implies the following assumptions: thinking skills are learnable and therefore it should be learned, all topics are appropriate for thinking if presented in a suitable context, all children after the age of 11 can deal with the abstract levels with differences in the amount of thinking, and that these learning strategies can be learned to improve the students' skills.

Resnick (1987), Miri et al., (2007), Ramirez \& Ganaden (2008) outlined the characteristics of higher-order thinking as follows:

- Higher-order thinking comprises mathematical logarithmic relationships, and the way of working is not completely predetermined.

- Higher-order thinking tends to be complex because it includes an analysis of complex situations and depends on the individual's mental judgments

- Higher-order thinking incorporates the self-organization of the thinking process that includes self-evaluation and this self-organization is closer to self-monitoring as it requires autonomy.

- Often this type of thinking gives multiple solutions instead of giving a unique one since it avoids simple solutions or formulations, that one issue often has several possible solutions.

- The task of the thinker is to create and discover meaning for the situation or cognitive experience (impose meaning) as it explains what cannot be explained.

- This mode of thinking often involves uncertainty because everything related to the available task is not known. Also, ignorance or creative emptiness leads to the discovery of meanings and ideas.

- This thinking tends to acknowledge the causal or logical relationships that govern the situation under investigation.

\subsection{Psychological Hardness}

Machuca (2010) defined psychological hardiness as the ability to respond and perform positively towards calamities, achievement despite missteps, and exceeded expectations significantly under negative conditions. In this context, many researchers agreed on some characteristics that distinguish those with high psychological hardiness as a commitment to others, courage, and competition, the ability to endure and resist, as well as the ability to find many alternatives to problems, personal attractiveness, persistence and challenge as they have personal achievement and a tendency towards optimism (Taylor, 1995; Bartone, 2007). 
Mukhaimar (1996) described psychological hardiness and its three dimensions as a psychological contract the individual commits towards himself, his goals, his values, and others. It reflects the individual's belief that he can control the events he experienced, and take the responsibility for the events that he exposes to as he admits that the changes in his life aspects are necessary for growth rather than considering it as a threat or disability. Procedurally in the current study, it is measured by the degree that the university students obtained on the psychological hardiness scale which has three dimensions: commitment, control, and challenge.

Additionally, psychological hardiness according to Kobasa et al. (1985) is a multidimensional structure consisting of commitment, control, and challenge. She asserted that these components are relevant and make an individual capable of facing environmental challenges and transforming life stressful events into opportunities for personal growth. Lack of these dimensions is described as psychological exhaustion. Moreover, this structure aims to reduce the impact of stress by changing the vision of stressful situations and to reduce the negative effect of life events through influencing both cognitive assessment and effective confrontation (Lambert et al., 2003). Muhammad et al. (2018) defined it as a personality system that can be developed for all individuals because it is an effective stress reliever which helps to continue and enhance performance, leadership, ethics, and health because it is a positive indicator for effective performance and life quality of those who suffer from serious diseases.

Taylor (1995) listed the characteristics of psychological hardiness as follows: the feeling of commitment or intent to push oneself to get involved in any new developments; the faith "belief" in control or the feeling that the person himself is the cause of the event that occurred in his life and that the person can influence his environment, and the desire to bring about change and confront activities that represent or serve as opportunities for growth and development. Van et al. (2006) added that the characteristics of psychological hardiness include positive emotion and sense of humor, possessing effective problems solving skills, believing that stress can increase the individual's strength, flexibility, accepting negative emotions and trying to overcome negative experiences, effective handling of stress and considering it as challenges should be confronted.

Kobasa et al. (1985) concluded that psychological hardiness consists of three dimensions: commitment, control, and challenge, and they are the most agreed upon in most studies that investigated psychological hardiness. These studies defined commitment as the general sense of purpose and participation in the life, it is a type of psychological contract that an individual adheres towards himself, his goals, values, and others around him. A high-commitment person tends to interpret interaction with people and events as exciting, worthwhile, and seeking active participation rather than withdrawal. While Control implies the belief in the individual's ability to influence the course of events and taking responsibility for the events that he is exposed to. Whereas the challenge includes considering new events and challenges as a significant opportunity for personal development and growth (Bartone, 2000; Bartone et al., 2012; Hystad et al., 2011; Maddi, 2002; Sandvik, 2019).

\subsection{Theoretical/ Conceptual Framework}

Reviewing literature revealed that there are no Arabic and Foreign studies- according to the researchers' knowledge- that dealt with thinking and psychological hardiness together, and because of the scarcity of studies dealing with these variables except the following studies study (Shaheen \& El Sayed, 2012; Muhammad, 2013; Hammad, 2015; Nasseem \& Khalid, 2010; Tugade \& Fredrickson, 2004) which linked psychological hardiness with thinking styles in general, the research objectives stem from the objectives of science; that the current research aimed at identifying the differences between males and females in higher-order thinking skills and psychological hardiness as well as identifying the extent to which higher-order thinking degrees and dimensions contribute in predicting the degrees of psychological hardiness of university students.

Consequently, the university student needs psychological hardiness more than any past academic years because he relies on himself in many different situations and problems, and as he exposes many stressful situations. Higher-order thinking skills are essential tools in a society characterized by rapid change, diversity of choices, and frequent decisions (Erikson, 1991). Besides, many students come to the university stage and cannot think effectively; although thinking, analysis, criticism, synthesis, designing, problem-solving; visualization of alternatives, and contradictions are among the most important functions of university education. Therefore, the current study seeks to investigate the extent to which higher-order thinking degrees contribute to predicting the psychological hardiness of university students and explore the relationship between the study variables.

This study hypothesizes that higher-order thinking degrees and dimensions contribute significantly to predicting the degrees of psychological hardiness of university students and that there are no statistically significant differences between the males and females university students' means of the scores in both higher-order thinking and psychological hardiness. 


\section{Method}

The researchers utilized the descriptive research methodology as it is the most appropriate approach to the nature of the current study.

\subsection{Research Participants}

This study conducted during the first semester of the academic year 2019/2020. To achieve the study objectives the researchers selected two groups of participants as follows:

- Sample of Verifying the Study Tools: to verify the study scales (300) university students (females=160, male $=140$ ) were selected from the grade of all scientific and literary departments at the Faculty of Education, Minia university with (age mean $=20.820, \mathrm{SD}=0.665$ ) for the whole sample, and female sample (age mean=20.887, $\mathrm{SD}=0.593$ ); while for male students (age mean $=20.742, \mathrm{SD}=0.733$ ). This sample is selected to ensure the validity and reliability of the current study tools to be applied to the basic study.

- The Basic Sample of the Study: To apply the research tools the researchers selected (485) male and female students from the third year enrolled in the Faculty of Education, Minia University with (age mean $=20.826, \mathrm{SD}=0.645$, female $=273$, male $=212$ ); regarding males (age mean $=20.750, \mathrm{SD}=0.680$ ) and for females (age mean $=20.886, \mathrm{SD}=0.610$ ).

\subsection{Research Hypotheses}

- Higher-order thinking degrees and dimensions contribute significantly to predicting the degrees of psychological hardiness of university students.

- There are no statistically significant differences between the mean scores of males and females in both higher-order thinking and psychological hardiness among university students.

\subsection{Research Instruments}

\subsubsection{A Higher-Order Thinking Scale (Prepared by the Researchers)}

After reviewing the previous studies, related literature and measures available in this field the researchers designed a higher-order thinking scale for university students as a tool to achieve the objectives of the current study through dividing higher-order thinking into two sections the first section regarding critical thinking which included (6) dimensions: knowledge, understanding logical rules, the ability to interpret, the affective, sensitivity towards problems, and the evaluation dimensions. While the second section concerning creative thinking which dealt with five dimensions: fluency, originality, flexibility, sensitivity to problems, and expansion (perceiving details), with five alternatives in front of each item. The students have to choose the most appropriate from his point of view. They are grading as follows: (5 always - 4 often - 3 sometimes -2 little - never 1 ). Then the psychometric properties of the higher-order thinking scale have been confirmed as follows:

\subsubsection{Scale Validity:}

- Face Validity: the scale presented in its initial form to 7 professors from the mental health and psychology departments to determine the suitability of the scale statements to measure higher-order thinking of university students. They recommended adding statements on the creative thinking section to be (31) items and modifying (4) items.

- Construct Validity: This was confirmed by calculating the correlation of the degree of each item to the dimension to which they belong to in both critical and creative thinking. Moreover, the correlation of critical and creative thinking with the overall degree of the scale was calculated. All correlation coefficients were statistically significant at the level of (0.01).

- $\quad$ Factorial Validity: The researchers verified the scale validity statistically through factorial validity after confirming the appropriateness of the sample and the scale for factorial analysis by using Kaiser-Meyer-Olkin (KMO) and Bartletts formulations (Glen,S. 2016). That factor analysis for the scale items (critical and creative thinking), (30) items for each section of higher-order thinking using the method of basic components of Hoteling. The researchers followed the" Gutman" criterion to determine the number of factors, where the factor is essential if its latent root is 1 or more. Then the factors were managed orthogonally for each section on critical and creative thinking with the Varimax method. Concerning critical thinking statements, factor analysis resulted in (6) factors, where factor load of 29 items was more than $(0.30)$ as follows: the first-factor flexibility, the second-factor understanding, the third-factor ability to interpret, the fourth factor the affective dimension, the fifth factor systematically solving-problems, and the sixth factor is evaluation. Thus, the number of scale statements in its final form was (29) items distributed into the 
six scale factors. The overall degree of the scale ranged from (29:125) according to a 5-point Likert scale (5 always - 4 often - 3 sometimes - 2 little - never 1). Concerning creative thinking section factor analysis resulted in five factors, where factor load of (30) items was more than (0.30), they are as follows: fluency, originality, flexibility, sensitivity to problems, and expansion. Accordingly, the number of items in its final form was (30) distributed into five factors of the scale, as the overall degree of the scale ranged from (30: 150) according to a 5-point Likert scale (5 always - 4 often - 3 sometimes - 2 little - never 1).

\subsubsection{Scale Reliability}

To confirm the higher-order thinking scale reliability the researchers utilized the Cronbach's Alpha and the Split half reliability methods on the research sample assigned for verifying the research tools that consisted of (300) third-year Faculty of Education students, Minia University. The reliability coefficients ranged from (0.601-0.923) for the critical thinking section and (0.643-0.938) for the creative thinking section. Consequently, the scale and its dimensions achieve high validity and reliability that enables it to be applied in the basic study.

\subsubsection{Psychological Hardiness Scale (by Mukhaimar, 1996)}

It is a measurement tool that presents a quantitative estimation of an individual's psychological hardiness. It consisted of 47 items that focus on aspects of an individual's psychological hardiness. The score for each item ranged between three degrees to one degree as follows: (3) always apply to me, (2) sometimes apply to me, and (1) never apply to me. That the total degree of the tool ranged between 47:141 scores. The high degree indicates the high respondent's awareness of his psychological hardiness. It is divided into three dimensions as follows: commitment, control, and challenge.

2.3.2.1 Scale Validity in the Current Study: The researchers verified the validity of this scale in the current study through internal consistency by calculating the correlation coefficient between the scale dimensions together, between the dimensions of the scale and the overall degree of the scale. All correlation coefficients were significant at the (0.01) level.

2.3.2.2 Scale Reliability in the Current Study: To ensure the scale reliability, the researchers utilized the Cronbach's Alpha equation to calculate the reliability coefficient of the scale on the sample of the study from Minia University students. All the alpha values for the scale and its dimensions are high and significant at the level of (0.01), and this indicated the scale high reliability.

\subsection{Analysis Methods}

To test the validity of the hypotheses, the SPSS was used to perform the statistical treatment where the t-test, the Pearson correlation coefficient, and the multiple regression analysis were calculated to verify the study hypotheses.

\section{Results}

3.1

Results of Validating the first Hypothesis "Higher-order thinking degrees and dimensions contribute significantly to predicting the degrees of psychological hardiness of university students": to verify this hypothesis, the researchers conducted multiple regression analyses using the stepwise method of selection. It is a method based on adding independent variables to the model one after the other. It includes building a complete model with all the independent variables and deleting the non-significant contributed variables one after the other. This resulted in the extraction of the only factor that is most contributive to predict the psychological hardiness which is the total degree of higher-order thinking where $\mathrm{R}=0.473$ and the following results are obtained:

Table 1. Results of the Variance Analysis for the Contribution of Higher-order Thinking and Its Dimensions in Predicting Psychological Hardiness

\begin{tabular}{cccccc}
\hline Source of Variance & Sum of Squares & DF & Mean Squares & F & Sig. \\
\hline Regression & 9627.37 & 1 & 9627.37 & & \\
Residual & 33414.23 & 483 & 69.18 & 139.16 \\
Total & 43041.60 & 484 & & \\
\hline
\end{tabular}

Note: Table 1 revealed the achievement of this hypothesis which stated that "Higher-order thinking degrees and dimensions contribute significantly in predicting the degrees of psychological hardiness of university students", that $\mathrm{f}=139.16$ which is significant t (0.01) level. 
Table 2. Results of Regression Analysis for the Contribution of Higher-order Thinking and Its dimensions in Predicting Psychological Hardiness

\begin{tabular}{ccccccc}
\hline Model & Beta & Regression Coefficient & $\mathrm{t}$ & Constant Variance & $\mathrm{R}$ & $\mathrm{R}^{2}$ \\
\hline Total Degree & 0.473 & 0.14 & 11.79 & 77.62 & 0.473 & 0.224 \\
\hline
\end{tabular}

Note: Table 3 indicated that the multiple correlation coefficient was (0.473) which was the highest one in all models. While the coefficient of R2 $=0.224$ and this means that that the independent variable (higher-order thinking) explains about (22.4\%) from the total variance of the research sample performance on the variable of psychological hardiness.

From the previous table, we can conclude the regression equation as follows:

$$
y=a+b x
$$

Where(y) is the value of the dependent variable (psychological hardiness), (x) is the value of the independent variable (the total degree of higher-order thinking), (b) the regression coefficient of the independent variable and the value of (a) is the constant regression= (77.62). So the formula is as follows:

$$
\text { Predicted Psychological Hardiness }(y)=0.14 \text { (the total degree of higher-order thinking+ } 77.62
$$

3.2

Results of validating the second hypothesis "There are no statistically significant differences between the mean scores of males and females in both higher-order thinking and psychological hardiness among university students": To validate this hypothesis, a t-test was used, and the following table illustrated the results:

Table 3. Arithmetic Mean, Standard Deviation, (t) value and Its Significance for the Differences between the Mean Scores of Males and Females in Higher-order Thinking and Psychological Hardiness $(n=485)$

\begin{tabular}{cccccccc}
\hline \multirow{2}{*}{ Variable } & \multicolumn{2}{c}{ Males $(\mathrm{n}=212)$} & \multicolumn{2}{c}{ Females=273) } & & \multirow{2}{*}{ Sig. } \\
\cline { 2 - 5 } & Mean & Std. Deviation & Mean & Std. Deviation & & t-value & not significant \\
Higher-order Thinking & 210.278 & 30.420 & 209.946 & 32.468 & & 0.149 & \\
Psychological Hardiness & 108.094 & 9.760 & 106.699 & 9.137 & & 1.618 & not significant \\
\hline
\end{tabular}

Note: It is clear from Table (3) that there were no statistically significant differences between males and females in higher-order thinking and psychological hardiness, and these results can be explained from the researchers' view as follows:

- Concerning higher-order thinking, this result is consistent with the results of (Jani \& Al-Ali, 2012; Al-Ghamdi \&El-Zebon, 2013) and inconsistent with the study of (El-Noab \& Hussien, 2013) which demonstrated that there were differences between genders in higher-order thinking. The researchers attribute this result to the nature of the content, teaching methods, evaluation methods in the University study which both males and females share. Especially that Minia University teaches males and females in the same hall with the same conditions, which makes them close in their higher-order thinking.

- Regarding the psychological hardiness variable, this result is consistent with the studies of (El-Tala'a and Dukhan, 2016; El-Wakeel, 2015) and inconsistent with the study of (Shaqurah and Alyan, 2012), which revealed that there were differences due to gender in psychological hardiness. The researchers attribute this result to the nature of the environment and living conditions in which they live. They were bringing up in the same conditions. The difficulties are the same for everyone and require strategies and methods to face, solve, and adapt to them. Moreover, educational, social, and cultural institutions are no longer limited to a certain gender. Rather, female students try to compete with males in overcoming difficulties and coping with them which consequently support their psychological hardiness equally to males.

Consequently, results demonstrated that there was a significant positive correlation between the degrees of higher-order thinking and psychological hardiness at the level of significance $(0.01)$. The researchers attributed this result to the fact that higher-order thinking skills are adaptive skills that contribute to controlling emotions and dealing effectively with stress. This is consistent with what was indicated by (Lipman, 1991; Newman, 1991). In addition to the results of (Shaheen \& El Saied, 2012; Muhammad, 2013; Hammad, 2015; Nasseem \& Khalid, 2010; Tugade \& Fredrickson, 2004) which linked psychological hardiness with some patterns, skills, and styles of thinking in general.

Moreover, individual with higher psychological hardiness characterized by the ability to achieve, create, perseverance, tendency to lead, the capability to make decisions and choose between several multiple alternatives, benefit from experiences of failure to develop themselves, the desire to explore the environment, know what they don't know, and concern for the environment and preserving it as well as effective participation in it. 
According to what was mentioned above the researchers acknowledged that individuals who have a high degree of psychological hardiness characterize by the ability to positively confront issues. Moreover, the degree of their hardiness reflects the extent of their belief in their effectiveness, their ability to optimize the use of their personal and environmental recourses, and their focus on problems or transformative methods that transfer higher pressures to fewer pressure experiences (Abdel Hamid \& Mustafa, 2009). Besides, critical thinking leads to the independence of the individual in his thinking, liberating him from self-centeredness, subordination, and impulsiveness to wide fields and encourages the spirit of research, inquiry, investigation, and discovery.

\section{Discussion}

The researchers revealed that there were no statistically significant differences between the degrees of males and females in the higher-order thinking and psychological hardiness due to gender variable (male/female). The researchers attributed this result to the nature of the university study from content, teaching methods, activities, evaluation, and the academic experiences in which males and females participate that makes them close in their higher-order thinking skills. In addition to the fact that the nature of the environment and living conditions in which they live are similar, as well as they share difficulties which require them to think in strategies and methods of facing, solve and adapt to such problems, which make them close in their psychological hardiness.

The researchers discovered a statistically significant positive correlation between the degrees of higher-order thinking and psychological hardiness. The researchers explained that higher-order thinking skills are an adaptive skill that contributes to controlling emotions and good handling of stress and life problems. Moreover, psychological hardiness can be predicted through higher-order thinking among university students, because the more students progress through their academic levels, the more they have experience and higher thinking skills; which leads to an increase in psychological hardiness that contributes to solving more problems and leads also to more adaptation to their academic environment and life.

Moreover, the university student needs psychological hardiness more than any previous stage as he depends on himself in a lot of situations and problems as well as he exposes to many stressful situations so that higher-order thinking is essential in a society which characterized by rapid change and diversity of choices and the large number of decisions where thinking, analyzing, criticizing, comparing, illustrating, designing, solving problems and contradictions as well as visualizing alternatives are the most important functions of the university.

\section{Further Suggestions}

In light of the results of the study, the researchers recommend the following:

- Urging those responsible for educational planning and policies in university education to include higher-order thinking skills in curricula and courses for their important role in developing the psychological hardiness of university students, as they have a new life at the university stage full of difficulties and challenges.

- Holding training courses and workshops for faculty members on how to train students in higher-order thinking skills that develop in the student performance and psychological hardiness.

- Enhancing psychological hardiness and address the causes and factors that lead to its decline among university students through employing academic experiences and student activities that develop problem-solving skills.

\section{Acknowledgments}

This publication was supported by the Deanship of Scientific Research at Prince Sattam bin Abdul-Aziz University, Alkharj, Saudi Arabia.

\section{Authors' Contributions}

This article is the outcome of the two authors' combined labor. Each author is responsible for 50 percent of the outcome.

\section{References}

Abbas, M. (2010). Psychological hardiness as a predictor to reducing stress and aggressive behavior among middle school teachers. Journal of the Faculty of Education, 26(1), 167-236. Retrieved from https://search.mandumah.com

Abdel Hamid, H., \& Mostafa, H. (2009). Foundations of wrestling training. Alexandria, Dar Al-Wafaa for Printing and Publishing.

Al-Atoum, A., Al-Jarrah, A., \& Bechara, M. (2007). Development of thinking skills (theoretical models and 
practical applications). Amman: Al Masirah House for Publishing and Distribution.

Al-Ghamdi, K., \& El-zebon, S. (2013). The effectiveness of a training program based on habits of the mind in improving higher-order thinking skills among a Jordanian sample of gifted students in leadership positions (Ph.D. degree thesis, International Islamic Science University, Amman).

Al-Tala'a, M., \& Dukhan, N. (2016). Spiritual intelligence and its relationship with psychological hardiness among students of the Islamic University of Gaza. Master's degree Thesis, Islamic University of Gaza.

Bartone, P. T. (2000). Hardiness as a resiliency factor for United States forces in the Gulf War. In J. M. Violanti, D. Paton, \& C. Dunning (Eds.), Posttraumatic stress intervention: Challenges, issues, and perspectives (pp. 115-133). Charles C Thomas Publisher. Retrieved from https://psycnet.apa.org

Bartone, P., Hystad, S., Eid, J., \& Brevik, J. (2012). Psychological hardiness and coping style as risk/resilience $\begin{array}{lllll}\text { factors for alcohol } \text { abuse. Military } & \text { Medicine, }\end{array}$ https://doi.org/10.7205/MILMED-D-11-00200

Bartone, T. (2007). Harnessing hardiness - psychological resilience in persons and organizations. Industrial College of the Armed Forces National Defense University Washington, DC, USA college students. Social Behavior and personality, 26(1), 51-56. https://doi.org/10.1207/s15327876mp1803s_10

Beyer, B. (1987). Practical Strategies for Teaching of Thinking. Boston. Retrieved from https://eric.ed.gov

El-Noab, N., \& Hussein, M. (2013). Habits of reason and higher-order thinking and their relationship to self-efficacy among students of colleges of education. Journal of Human Sciences, (19), 149-172. Retrieved from https://search.mandumah.com

El-Wakeel, H. (2015). Some predictors of psychological resilience among a sample of university students. Master's degree Thesis, Menoufia University.

Erikson, G. (1991). Choice and Perception of Control: The Effect of Thinking Skills Program on the Locus of Control, Self-Concept and Creativity of Gifted Students. Gifted Education International, 6, 135-142.

Glen, S. (2016). Kaiser-Meyer-Olkin (KMO) Test for Sampling Adequacy. Retrieved from https://www.statisticshowto.com/kaiser-meyer-olkin/

Hammad, A. (2015). Positive thinking, psychological hardiness, and their relationship to some variables among the students of Al-Neelain University. Master's degree thesis, Al-Neelain University.

Hystad, S., Eid, J., Laberg, J., \& Bartone, P. (2011). Psychological hardiness predicts admission into Norwegian $\begin{array}{lllll}\text { military } & \text { officer } & \text { schools. } & \text { Military } & \text { Psychology, }\end{array}$ https://doi.org/10.1080/08995605.2011.589333

Jani, N., \& Al-Ali, M. (2012). The effectiveness of a training program based on habits of the mind in developing high-level thinking skills for prep students. Ph.D. degree thesis, Al-Mustansiriya University.

Kobasa, S., Maddi, S., Paccetti, C., \& Zola, M. (1985). Effectiveness of hardiness, Exercise and social support as Resources against illness. Journal of Psychometric Research, 29(5), 525-533. https://doi.org/10.1016/0022-3999(85)90086-8

Lambert, A., Lambert, E., \& Yamase, H. (2003). Psychological hardiness, Work place and related stress reduction strategies. Journal of Nursing and Health Sciences, 5(2), 181-184. https://doi.org/10.1046/j.1442-2018.2003.00150.x

Lipman, M. (1991). Thinking in education. New York, NY, US: Cambridge University Press. https://doi.org/10.1017/CBO9780511840272

Machuca, R. (2010). Resilience Characteristics of Master's-Level Counseling Students. Doctoral dissertation, University of New Orleans. Retrieved from https://scholarworks.uno.edu

Maddi, S. (2002). The story of hardiness: Twenty years of theorizing, research, and practice. Consulting Psychology Journal: Practice and Research, 54(3), 175-185. https://doi-org.sdl.idm.oclc.org/10.1037//1061-4087.54.3.175

Maddi, S. (2013). Personal hardiness as the basis for resilience. In Hardiness (pp. 7-17). Springer, Dordrecht. https://doi.org/10.1007/978-94-007-5222-1_2

Miri, B., David, B., \& Uri, Z. (2007). Purposely Teaching for the Promotion of Higher- Order Thinking Skill: A Case of Critical Thinking. Research Science Education, 37(4), 353-369. https://doi.org/10.1007/s11165-006-9029-2 
Muhammad, Z. (2013). Psychological hardiness and its relationship to the meaning of life in the light of positive thinking among a sample of university students. Master's Thesis, Aswan University.

Muhammad, A., Suleiman, S., \& Al-Shaarawi, S. (2018). Marital compatibility and its relationship to psychological rigidity, empathy and coping strategies for university students. Journal of Scientific Research in Education, 6(19), 89-116.

Mukhaimar, I. (1996). Psychometric Scale. Cairo, the Egyptian Renaissance Library.

Naseem, Z., \& Khalid, R. (2010). Positive Thinking in Coping with Stress and Health outcomes: Literature Review. Journal of Research and Reflections in Education, 4(1), 42-61. Retrieved from http://www.ue.edu.pk/jrre

Newman, F. (1991). Promoting Higher Order Thinking Skills in Social Studies: Overview of A Study of 16 High School Departments. Journal of Theory and Research in Social Education, 4(19), 324-340. https://www.tandfonline.com/doi/abs/10.1080/00933104.1991.10505645

Nickerson, R. (1999). Enhancing creativity. In R. J. Sternberg (Ed.), Handbook of creativity (pp. 392-410). Cambridge: Cambridge University Press.

Paul, R., \& Binker, A. (1990). Critical thinking: What every person needs to survive in a rapidly changing world. Rohnert Park, Calif: Center for Critical Thinking and Moral Critique, Sonoma State University. Retrieved from https://eric.ed.gov

Ramirez, R., \& Ganaden, M. (2008). Creative Activities and Students Higher Order Thinking Skills. Education Quarterly, 66(1), 22-33. Retrieved from https://eric.ed.gov

Ramos, J., Dolipas, B., \& Villamor, B. (2013). Higher Order Thinking Skills and Academic Performance in Physics of College Students: A Regression Analysis. International Journal of Innovative Interdisciplinary Research, 4, 48-60. Retrieved from https://www.researchgate.net

Resnick, L. (1987). Education and Learning to Think. Washington, DC: National Academy Press.

Shaheen, J., \& El Saied, N. (2012). Methods of thinking according to the theory of mental self-control and psychological hardiness among students of the Faculty of Education, Al-Azhar University: a predictive differential study. Journal of the College of Education, I(149), 43-95.

Shaqqura, Y., \& Alian, M. (2012). Psychological resilience and its relationship to contentment with life among Palestinian university students in Gaza governorates. Master's degree thesis, Al-Azhar University in Gaza.

Swartz, R., \& Perkins, D. (1990). Teaching Thinking: Issues and Approaches. U.S.A. Pacific Grave, CA: Midwest Publication.

Taylor, S. (1995). An Analysis of a Relaxation Stress Control Program in an Alternative Elementary School. Dissertation Abstracts International, 35(50), 169-210. Retrieved from https://www.semanticscholar.org

Tugade, M., \& Frederickson, B. (2004). Resilient Persons use positive emotions to bounce back from negative emotions experiences. Journal of Personality and social psychology, (86), 320-333. https://doi.org/10.1037/0022-3514.86.2.320

Van, G., Puijter, M., \& Smeets, C. (2006). Citizens and resilience Amsterdam. Dutch Knowledge and Advise center.

Yee, M., Yunos, J., Othman, W., Hassan, R., Tee, T., \& Mohamed, M. (2015). Disparity of learning styles and higher order thinking skills among technical student, Procedia - Social and Behavioral Sciences, (204), 143-152. https://doi.org/10.1016/j.sbspro.2015.08.127

Zohar, A., \& Dori, Y. (2003). Higher order thinking skills and low-achieving students: Are they mutually exclusive? Journal of the Learning Sciences, 12(2), 145-181. Retrieved from https://www.tandfonline.com/doi/abs/10.1207/S15327809JLS1202_1

\section{Copyrights}

Copyright for this article is retained by the author(s), with first publication rights granted to the journal.

This is an open-access article distributed under the terms and conditions of the Creative Commons Attribution license (http://creativecommons.org/licenses/by/4.0/). 